\section{Psicologia Escolar \\ e Educacional}

ARTIGO

DOI: http://dx.doi.org/ 10.1590/2175-35392021223865

Localizador - e223865

\title{
OS OBJETOS SEM SIGNIFICAÇÃO LÚDICA ESPECÍFICA NA BRINCADEIRA
}

\author{
Suzana Marcolino ${ }^{1} \mathbb{D}$; Suely Amaral Mello ${ }^{1} \mathbb{D}$
}

\section{RESUMO}

O artigo apresenta resultados de pesquisa de pós-doutoramento com objetivo de verificar se a apresentação de objetos sem significação lúdica específica articulada à retirada gradual de brinquedos cria uma circunstância em que o uso dos primeiros potencializa processos psicológicos em desenvolvimento na criança. O referencial teórico é a Psicologia Histórico-Cultural, mais precisamente a teoria de D. B. Elkonin sobre a brincadeira. A metodologia inspirase na experimentação pedagógica: cria-se uma condição semelhante ao contexto pedagógico e realizam-se ações com vistas a conhecer seus efeitos. Participaram da pesquisa crianças entre 4 e 5 anos. Os resultados apontam que a retirada de brinquedos provoca a utilização de objetos sem significação específica e potencializa o uso da palavra nas situações nas quais a criança procura um objeto substituto para o brinquedo ausente. Essa ação da criança é indício que está dando passos rumo ao pensamento conceitual.

Palavras-chave: educação infantil; brincadeira; psicologia histórico-cultural.

\section{Objects without specific ludic significance in play}

\begin{abstract}
The article presents the results of postdoctoral research with the objective of verifying whether the presentation of objects without specific playful meaning articulated to the gradual removal of toys creates a circumstance in which the use of the former potentiates psychological processes in development in the child. The theoretical framework is Historical-Cultural Psychology, more precisely D. Elkonin's theory of play. The methodology is inspired by pedagogical experimentation: a similar condition to the pedagogical context is created and actions are taken in order to know its effects. Children between 4 and 5 years old participated in the research. The results show that the removal of toys causes the use of objects without specific meaning and enhances the use of the words in situations in which the child seeks a substitute object for the missing toy. This child's action is an indication that he/she is taking steps towards conceptual thinking.
\end{abstract}

Keywords: early childhood education; playing; historical-cultural psychology.

\section{Los objetos sin significación lúdica específica en el juego de niños}

\begin{abstract}
RESUMEN
En el artículo se presenta resultados de investigación de post doctoramiento con objetivo de verificar si la presentación de objetos sin significación lúdica específica articulada a la retirada gradual de juguetes crea una circunstancia en que el uso de los primeros potencializa procesos psicológicos en desarrollo en el niño. El referencial teórico es la Psicología Histórico-Cultural, más precisamente la teoría de D. B. Elkonin sobre el juego de niños. La metodología se inspira en la experimentación pedagógica: se crea una condición semejante al contexto pedagógico y se realizan acciones con vistas a conocer sus efectos. Participaron de la investigación niños entre 4 y 5 años. Los resultados apuntan que la retirada de juguetes provoca la utilización de objetos sin significación específica y potencializa el uso de la palabra en las situaciones en las cuales el niño procura un objeto substituto para el juguete ausente. Esa acción del niño es indicio que está dando pasos rumbo al pensamiento conceptual.
\end{abstract}

Palabras clave: educación infantil; juego; psicología histórico-cultural.

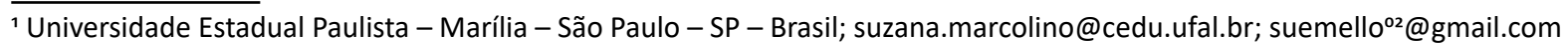




\section{INTRODUÇÃO}

Recentemente as Diretrizes Nacionais Curriculares para a Educação Infantil (Brasil, 2010) destacaram a necessidade de assegurar práticas condizentes com as formas de aprendizagem e desenvolvimento das crianças pequenas, sugerindo as interações e a brincadeira como eixos norteadores da prática pedagógica na Educação Infantil, o que é, sem dúvida, um avanço. Tal proposta orienta que a prática pedagógica na Educação Infantil deve levar em conta os processos criativos e imaginativos em tudo o que se propõe às crianças (Gobbi, 2010) e, também, cuidar dos espaços, tempos, objetos e relações para que elas brinquem na escola.

No entanto, no Brasil, o quadro típico das escolas de Educação Infantil ainda apresenta antecipação de conteúdo, espaços, rotinas, organização do tempo e relações próprias do Ensino Fundamental, ignorando as formas de aprender das crianças (Marcolino \& Mello, 2015). Por isso, o debate e a pesquisa sobre a brincadeira precisam ser assumidos como uma prioridade no que se refere à prática pedagógica na Educação Infantil.

Pesquisadores da área identificam importantes contribuições da Teoria Histórico-Cultural para o debate teórico-metodológico sobre a brincadeira na Educação Infantil. Para Aquino (2015), as elaborações vigotskianas sobre a brincadeira e suas relações com o pensamento e a fala fornecem elementos teóricos para afirmar a brincadeira e as interações como eixos norteadores das propostas pedagógicas destinadas às crianças, pois apontam que, nesse momento da vida, as crianças aprendem por meio de suas experiências e vivências, sendo a brincadeira a atividade na qual a criança constrói o conhecimento do mundo via imaginação.

Marcolino, Barros e Mello (2014) enfatizam as contribuições de Elkonin (2009) e consideram que, quando as crianças constroem situações imaginárias para interpretar papéis sociais, processos psíquicos e da personalidade ganham nova qualidade.

As mesmas autoras sugerem a criação de espaços e tempos para brincar, que sejam geridos pelas crianças. Nesse sentido, o papel do professor concentra-se na organização do espaço e dos materiais para que as crianças brinquem na escola (Teixeira \& Alves, 2008; Marcolino, 2013). Marcolino (2013) sustenta que o professor atue na organização do tempo, espaço, objetos e relações, destacando que todas as atividades que possibilitem o conhecimento do mundo pela criança e o encontro com a cultura (contar histórias, as visitas de estudo, o teatro, a experiência estética, a relação com a cultura escrita, projetos de pesquisa) influem no conteúdo das brincadeiras, pois servem de material para que as crianças possam criar ricas situações imaginárias.

Tomando as pesquisas acima como referência, é possível afirmar que a escola, professoras e professores das crianças precisam comprometer-se com o conhecimento do mundo pelas crianças e com as condições na quais elas brincam: como o tempo, os espaços, as relações e os objetos. A presente pesquisa insere-se no conjunto de preocupações sobre a brincadeira na Educação Infantil e, mais especificamente, preocupa-se com os objetos oferecidos para as crianças brincarem.

Na década de 1990, a utilização dos chamados objetos não-estruturados foi foco de estudos, principalmente no campo da Psicologia. Para Mcloyd (1983), tais objetos contrastam com os brinquedos, possuidores de alto valor simbólico. Fundamentando-se nessas ideias, Verba (1993) observou brincadeiras infantis em que as crianças utilizavam objetos como caixas e cilindros de papelão e verificou o desenvolvimento da situação imaginária. Outra pesquisa sob essa perspectiva é de Mello (1994), que constatou que os objetos não estruturados podem incitar brincadeiras. Tais pesquisas preocuparam-se com a descrição das brincadeiras, sem analisar porque as crianças fazem uso de tais objetos e o papel deles na ação lúdica, resultando em conclusões bastante gerais sobre o uso desses objetos na brincadeira.

Gosso, Morais e Otta (2006), partindo das ideias vigotskianas, compreenderam que tais objetos apoiam o trabalho com os significados na brincadeira, atuando como pivôs para a situação imaginária, possibilitando um maior número de transformações de significado do que os brinquedos. As autoras constataram que, em grupos culturais distintos, crianças utilizam pivôs de diferentes materiais e que o uso deles nas brincadeiras reflete a individualidade da criança e os valores de sua cultura.

No presente artigo, denominaremos tais objetos como sem significação lúdica específica, pautandonos na discussão realizada por Elkonin (2009), pois consideramos que essa designação capta melhor o papel desses objetos na ação lúdica e como afetam a aprendizagem e o desenvolvimento. Conforme Elkonin (2009), a atuação com os brinquedos é importante, pois, ao apresentar as regras dos papéis sociais, sugere à criança certa forma de atuar. No entanto, a criança torna-se cada vez mais consciente dos significados, o que a torna capaz de aplicá-los aos objetos (Elkonin, 2009). Assim, os objetos que não possuem uma significação específica ganham significação no interior da situação imaginária. Nesse processo, ocorre um distanciamento entre o objeto real e seu modo de emprego inicial e, no segundo momento, a separação entre a palavra e o objeto, sendo que a palavra se torna, não a imagem do objeto, mas a complexa rede de possibilidades de ação com eles. Por isso, a ação na brincadeira é plástica, transmitindo o significado geral da ação (dar de comer, colocar para dormir).

Pela importância do uso de objetos sem significação 
lúdica específica na aprendizagem e desenvolvimento da criança, é interessante inseri-los na brincadeira que acontece na escola da infância. Entretanto, os resultados da pesquisa de Marcolino (2013) geram dúvidas sobre a forma de apresentar esses objetos no contexto pedagógico. A pesquisadora constatou que, apenas oferecer esses objetos juntamente com os brinquedos não implica necessariamente na utilização que potencialize o trabalho com os significados.

Lança luz à questão a sugestão de Elkonin (2009) de que os brinquedos devem ser gradualmente retirados, em consonância com fases da brincadeira que as crianças já são capazes de superar.

Mas, quais brinquedos devem ser prioritariamente retirados?

Para Elkonin (2009) brinquedos temáticos são aqueles que propõem uma série de ações para a criança: ao deparar-se com uma boneca pode-se alimentá-la, colocá-la para dormir etc. Há um subtipo de brinquedo temático, que são aqueles que o autor denominou como brinquedos que determinam ações concretas (Elkonin, 2009). Esses brinquedos sugerem à criança uma ação específica com eles. Por outro lado, criam condições para a criança engajar-se em ações com outros brinquedos.

Comparando funcionalmente os dois tipos de brinquedos, temos que o primeiro enseja várias ações em que o alvo é o mesmo brinquedo. Com o segundo tipo, a criança pode realizar uma ação que tem por alvo outro brinquedo e/ou objeto ou o companheiro de brincadeira, por exemplo, dar de comer a boneca, no caso de uma colher de brinquedo, ou colocar o bolo no prato e oferecê-lo a alguém, sendo o prato o brinquedo que determina ações concretas. Assim, parece-nos que o fato desses brinquedos estarem relacionados a outros, torna-os candidatos a ser preferencialmente retirados, pela função que ocupam entre os objetos da brincadeira.

A pesquisa de Frádkina (1946 por Elkonin, 2009) corrobora essa ideia, pois evidenciou que as crianças recorrem a objetos sem significação específica em ações com brinquedos, nas quais esses são o alvo da ação, entretanto, falta um brinquedo para completá-la. Por exemplo, para pentear a boneca (brinquedo temático alvo da ação) usa-se uma régua, na falta do pente (brinquedo temático que determina ações concretas).

Fundamentando-nos em Frádkina (1946, citada por Elkonin, 2009) e Elkonin (2009), construímos a hipótese de que a apresentação dos objetos sem significação lúdica específica deve ocorrer, prioritariamente, articulada à retirada dos brinquedos que têm outro brinquedo como alvo da ação, ou seja, os que determinam as ações concretas.

\section{METODOLOGIA}

A metodologia da pesquisa inspirou-se na experimentação didático-pedagógica. Nesse tipo de metodologia, cria-se uma situação semelhante ao contexto pedagógico, com o intuito de experimentar ações e conhecer seus efeitos para a aprendizagem e desenvolvimento das crianças. Essa proposta tem como núcleo a ideia vigotskiana de que interações com parceiros mais experientes da cultura possibilitam que processos psíquicos se movimentem, atingindo novos níveis de desenvolvimento.

\section{A situação criada}

Organizamos um cenário sugerindo a brincadeira de cuidados com a casa e a interpretação das relações familiares. O cenário foi composto pelos seguintes brinquedos $^{1}$ : um fogão, dois armários, uma máquina de lavar, uma tábua de passar roupa com o ferro, uma mesa e cadeiras, bolo ${ }^{2}$, frutas ${ }^{3}$, legumes ${ }^{4}$ e latinhas de suco, caixinhas que representavam alimentos industrializados (como gelatina, cereal, macarrão etc.), copos, panelas talheres, pratos, duas bonecas, um conjunto de ferramentas, uma carriola, um carrinho de feira, duas cestinhas de supermercado, um regador, vassoura e rodo. E pelos seguintes objetos reais: rolo de pintura de parede, almofadas de tamanhos variados, um espelho, um telefone, uma mamadeira, um minibatedor de ovos, pente, escova, bolsas e chapéus, artigos de decoração como vasos para flores, tapetes e toalhas de mesa.

Denominamos de primeira fase da pesquisa os quatro encontros, nos quais propusemos brincar com os brinquedos e objetos reais existentes no cenário. Nesses encontros, observamos a utilização dos brinquedos com objetivo de avaliar quais poderiam ser retirados nos encontros seguintes.

Denominamos segunda fase da pesquisa o conjunto de sete encontros, quando procedemos a retirada gradual dos brinquedos utilizados para completar ações, inserimos os objetos sem significação específica e observamos a brincadeira com os brinquedos, objetos reais e esses objetos. Os encontros, das duas fases, tiveram de uma hora a uma hora e vinte minutos de duração.

Os primeiros brinquedos retirados foram os utensílios de cozinha: em primeiro lugar as facas, depois todos os talheres, em seguida, copos, pratos e panelas e o ferro

\footnotetext{
${ }^{1}$ Todos os brinquedos foram adquiridos com a taxa de bancada e doados para uma escola pública de Educação Infantil, após conclusão da pesquisa.

${ }^{2}$ Brinquedo composto de quatro partes unidas por velcro, com o qual as crianças podiam fazer de conta que cortavam pedaços.

${ }^{3}$ Brinquedo composto por duas partes, unidas por velcro, com o qual as crianças podiam fazer de conta que o cortavam pelo meio (banana, pera, limão etc.).

${ }^{4}$ Brinquedo composto por duas partes, unidas por velcro, com o qual as crianças podiam fazer de conta que o cortavam pelo meio (milho, pimentão, tomate etc.).
} 
de passar, por fim, as ferramentas. Esses brinquedos são aqueles que, supusemos, teriam um impacto maior, pois as crianças necessitariam deles para complementar as ações lúdicas e isso faria com que procurassem algum substituto. A remoção era feita antes da chegada das crianças para o encontro. Os objetos sem significação específica foram apresentados em cestos na lateral do cenário.

Os objetos sem significação lúdica específica inseridos foram: canudos plásticos de tamanhos variados, palitos tipo de sorvete, tampinhas, gravetos, cabo de vassoura cortado em tamanhos diversos e lixados, cilindros de papelão de tamanhos diversos, régua, tubos e recipientes plásticos de tamanhos e formatos variados, retalhos de tecido de tamanhos variados, caixas de papelão de tamanhos e formatos diversos, isopor, porta-copos de madeira, suporte para mouse de computador, porta escova de dentes, uma mola de ferro, apoios para mouse de computador.

\section{Participantes, local e forma de registro}

Convidamos para participar da pesquisa, crianças entre quatro anos e três meses a cinco anos matriculadas em uma escola pública de Educação Infantil de um município de médio porte do interior paulista ${ }^{5}$. Os encontros ocorreram numa sala na própria escola, no período da manhã. Todos os encontros foram filmados e fotografados pela auxiliar de pesquisa. Como estratégia auxiliar de registro, ao final de cada encontro, a pesquisadora elaborava uma ata descritiva, narrando os principais eventos do dia relacionados aos interesses da pesquisa.

\section{Questões éticas na pesquisa com crianças}

Considerando os direitos e a capacidade das crianças em decidirem sobre sua participação, além do consentimento dos pais, foi elaborada uma condição para que pudessem dar seu assentimento. Antes da primeira fase, dois encontros foram realizados com o intuito de apresentar o local, o cenário, as atividades e os objetivos da pesquisa.

Nesses encontros, além de as crianças brincarem no cenário, foi destacado um tempo para conversar sobre a pesquisa. No primeiro encontro, a conversa girou em torno do que um pesquisador faz. Uma das crianças verbalizou que pesquisadores "mexem no computador". A pesquisadora perguntou para o grupo se concordava com a colega. Eles responderam que sim. Conversou-se que pesquisadores utilizam o computador para fazer anotações sobre o que observam e descobrem e que existem pessoas que fazem pesquisas na própria escola. Depois, foi anunciado que, nesse caso, a pesquisadora

${ }_{5}^{5}$ O processo foi submetido ao comitê de ética, via plataforma Brasil e obteve aprovação. estava realizando uma pesquisa para encontrar formas de fazer uma boa escola para as crianças, principalmente para brincarem. Por isso, iríamos brincar com brinquedos e materiais diferentes. Também foi explicitado que a participação não era obrigatória e que se não quisessem vir a um dos encontros, não haveria nenhum problema.

No fim do segundo encontro, a pesquisadora perguntou para as crianças se aceitavam participar de mais encontros como aqueles. Quis também saber do que mais gostaram no dia. Elas responderam que gostaram de tudo e pediram para a pesquisadora trazer todos os brinquedos no dia seguinte. As respostas das crianças evidenciaram o desejo em participar dos encontros, demonstrando, portanto, o assentimento.

\section{Procedimentos para análise}

Todas as sessões foram transcritas para análise. A partir das transcrições, destacamos situações, chamadas cenas, em que as crianças se relacionaram com os objetos sem significação lúdica específica. Inspirando-nos no trabalho de Moura (2004), adotamos que as cenas podem se traduzir em frases, diálogos entre as crianças ou entre as crianças e a pesquisadora, ações e relações lúdicas que se relacionam com o objeto de estudo desse trabalho. A partir dessas cenas, construímos episódios. Tais episódios articulam cenas que pretendem demonstrar como as ações da pesquisadora afetaram a atividade infantil e em que sentido.

No presente artigo, apresentamos os episódios que mais ilustram os achados da pesquisa. São eles: (i) "A brincadeira com os brinquedos no cenário", no qual identificamos os brinquedos que determinam as ações concretas mais utilizados pelas crianças na primeira fase da pesquisa; (ii) "A utilização dos objetos conforme o que se pode fazer com eles", que articula cenas permitindo a análise das primeiras formas de utilização dos objetos sem significação lúdica específica, com a retirada dos brinquedos, e; (iii) "A ausência de brinquedos e a procura de um substituto", que evidencia o processo de uso da palavra para o encontro de um objeto capaz de substituir o brinquedo.

\section{RESULTADOS E DISCUSSÃO}

Na primeira fase, os brinquedos mais utilizados pelas crianças foram os utensílios de cozinha e as ferramentas: em todos os encontros a mesa foi preparada para refeições e as crianças construíram argumentos em torno de situações de alimentação. No primeiro e segundo encontros, as crianças construíram um enredo em que acontecia uma viagem à praia e organizaram e pintaram o apartamento onde iam passar as férias. Nesses dias, a mesa também foi posta e, aparecem na atuação delas, os brinquedos que imitavam ferramentas. Nos últimos dois encontros, a brincadeira de família predominou, com o arranjo da mesa, ações lúdicas de cozinhar e servir refeições. 
Fase 1 - Episódio 1 - Brincadeira com os brinquedos do cenário.

Cena 01

Encontro 01

Margarida senta-se à mesa, enquanto Catarina coloca sobre ela copos de brinquedos que imitam taças, um pequeno jarro de metal e xícaras. Margarida serve suco. João diz: "Tem ferramentas para todo mundo brincar". Catarina encontra a mamadeira que está no armário: "Olha, uma mamadeira!". Margarida pega a xícara e faz que bebe, depois levanta-se, aproxima-se da pequena tábua de passar, pega o ferro de brinquedo e faz que passa a roupa. Em seguida, vai até o fogão e começa a fazer que cozinha. Catarina guarda a mamadeira e coloca mais pratos, copos e talheres na mesa. Rosa está com uma panela de pressão e uma colher de brinquedo. Mexe a colher dentro da panela e senta-se à mesa, em seguida faz que serve os pratos.

Cena 02

Encontro 01

Catarina para Margarida: "Espera filhaaa, você tem que pôr um chapéu!". Coloca o chapéu na cabeça de Margarida. João: "Tem que colocar o chapéu, senão não vai na praia, porque hoje a gente tá de férias". Catarina: "É, e a gente vai na praia! Eu vou fazer a mala". Catarina começa a pegar os utensílios de brinquedos que estão em cima da mesa. Margarida reclama. Catarina: "Eu estou fazendo a mala, não reclama!" Rosa mexe com a colher em um pote de brinquedo: "Eu sou a mãe!". Catarina: "Finge que a gente já tá na praia". João: " $A$ gente morava em um apartamento!". (...) Catarina: "Chegamos pessoal! Todo mundo chegou!". Margarida coloca a pequena tábua de passar em seu lugar no cenário. Catarina: "Vamos fazer coisas!". Coloca um pote no forno. João: "Eu tô com fome!". Rosa: "Eu vou fazer o bolo!". João pega o pincel e o rolo de pintura e faz que está pintando a casa. Margarida pega ferramentas e faz que arruma a máquina de lavar. Rosa para João: "Quer que eu ajude você?". João não responde. João coloca o rolo de pintar no chão e pega o alicate. Faz com alicate que está apertando um parafuso da mesa. Rosa pega o rolo de pintar e diz: "Enquanto isso, eu vou pintando, pega o rolo!". Pega o rolo vai até a parede e faz que pinta.

Cena 03

Encontro 2

Catarina coloca quatro copos de brinquedo sobre a mesa. Volta para o armário. Rosa faz que cozinha no fogão. Mexe com a colher na panela. Catarina coloca pratos na mesa. João ajuda Catarina a organizar a mesa. As crianças definem os papéis. Rosa põe o jarro em cima da mesa. Sentam para a refeição. Fazem que tomam o suco com os copos.

\section{Cena 04}

Encontro 3

Rosa pega o bolo de aniversário: "Olha o nosso bolo que eu fiz aqui". Catarina com talheres na mão: "Eu tô fazendo uma torta". Pega uma faca, corta as frutas e coloca na panela. João coloca o pimentão dentro da panela. Catarina: "Não põe o pimentão, não tem pimentão na salada de fruta". Rosa coloca pedaços de bolo em pratinhos. Paulo faz que cozinha no fogão utilizando os talheres para mexer nas panelas. João: "Vai ter salada de fruta e salada de comida".

Identificamos que os talheres, copos, ferramentas, pratos, ferro de passar de brinquedo cumpriram nas ações das crianças na brincadeira a função de completar as ações, constituindo-se como brinquedos que determinam as ações concretas. Assim, decidimos por retirá-los.

O episódio 2 apresenta as primeiras formas de as crianças se relacionarem com esses objetos, inseridos pela pesquisadora.

Fase 2 - Episódio 2 - Utilização dos objetos conforme o que se pode fazer com eles.

\section{Cena 01}

Encontro 01

Ação da pesquisadora: retirada das facas de brinquedo e inserção dos objetos sem significação específica.

Margarida anda pelo cenário. Vai até os objetos trazidos pela pesquisadora. Pega um conjunto de porta-copos de madeira. Vai até Catarina: "Olha o que achei, dá para pôr a comida". Catarina pega o conjunto de porta-copos, coloca-os em cima da mesa como se fossem pratos. Margarida volta ao cesto. Está com uma caixa de óculos na mão e dois potes de iogurte. Põe na mesa: "Olha o que achei lá!". Margarida continua trazendo objetos. Traz um rolo de papel toalha de cozinha. Mostra para Catarina: "Olha!". Põe em cima da mesa.

\section{Cena 02}

\section{Encontro 01}

Ação da pesquisadora: retirada das facas de brinquedo e inserção dos objetos sem significação específica.

João pega um rolo de papel toalha de cozinha. Coloca na boca e brinca com o som: "Tututu....Tututu". Catarina puxa da sua mão: “É negócio de papel!". João e Margarida seguem manipulando os objetos. Margarida anda com dois apoios de mouse na mão e diz: "Dá para colocar comida aqui!". Margarida pega vários objetos e os leva para o cenário.

Em experimentos realizados por Vigotski (1934, citado por Elkonin, 2009) e Lukov (1937, citado em Elkonin, 2009), com o objetivo de esclarecer o uso da palavra na brincadeira, contavam-se histórias para as crianças usando, para representar o enredo, objetos 
conhecidos das crianças. Para cada objeto foi dada uma denominação lúdica (um livro significava uma casa; um molho de chaves, crianças; um lápis, um termômetro). 0 experimento de Lúkov (1937, citado por Elkonin, 2009) apresentava um refinamento. Sendo a quantidade de objetos oferecida às crianças para que contassem a história, restrita e com a inserção de mais personagens pela pesquisadora, as crianças precisavam utilizar objetos que já haviam sido denominados, forçando a mudança da denominação lúdica destes.

Os resultados do experimento vigotskiano colocaram em evidência a questão do papel das ações no estabelecimento da relação entre o objeto e a palavra: os objetos são aceitos pelas crianças como substitutos dos reais, desde que se possa realizar, com eles, a mesma ação ou ação semelhante. Isso significa que a experiência da criança "[...] consubstanciada e sistematizada na palavra [...]" influi no uso lúdico dos objetos (Elkonin, 2009, p. 333). Lúkov (1937, citado por Elkonin, 2009), por sua vez, conclui que o fator determinante para que se possa incluir o objeto sem significação específica é o fato de ele poder ser inserido no sistema de relações lúdicas criadas na situação imaginária. No entanto, isso também depende da experiência anterior da criança com os objetos: é preciso conhecer os objetos, saber seus usos sociais para poder inseri-los nas relações estabelecidas entre os objetos na brincadeira.

Nos primeiros encontros em que os objetos sem significação lúdica específica foram inseridos, as crianças os exploraram e predominou, entre elas, o debate sobre as possibilidades de uso de cada um ou o que se poderia fazer com eles. Assim, os apoios para mouse "podem servir para pôr comida". João usa o rolo de toalha de papel de cozinha para produzir som.

A novidade em ter os materiais diferentes no cenário para a brincadeira atraiu as crianças: elas os manipularam e deduziram o que poderiam fazer com eles. Nessas cenas não há o desenvolvimento de uma situação imaginária com enredo e argumento. Assim, os objetos não podem ser inseridos na rede de relações lúdicas, permanecendo o debate e a experimentação das ações possíveis com os objetos, sem realizar denominação lúdica. Parece, então, que sem um enredo criado e desenvolvido para a brincadeira, fortalecem-se os nexos entre ação e objeto.

Episódio 03: A ausência dos brinquedos e a procura por um substituto.

\section{Encontro: 01}

Ação da pesquisadora: retirada das facas de brinquedo e inserção dos objetos sem significação lúdica específica.

Cena 01
Paulo brinca de cozinhar. Vai até a pesquisadora e pergunta onde estão as facas. A pesquisadora responde: "Hoje, eu não trouxe. Vê se ali (aponta para os objetos trazidos) tem alguma coisa que dê para usar como faca". Paulo vai até o cesto. Encontra um palito de sorvete, leva para a mesa, coloca do lado do prato. Vai para o fogão faz que cozinha.

\section{Encontro: 04}

Ação da pesquisadora: retirada dos copos, pratos, panelas e ferro de passar.

Cena 02

Paulo coloca o bolo em cima da mesa, diz para Catarina: "Precisa de uma faca". Vai até o cesto. Pega um palito. Cantam parabéns, corta-se o bolo com palito. Paulo corta fatias do bolo e coloca sobre o porta-copos de madeira. Fazem que come. Paulo diz sorrindo: "Agora, precisa escovar os dentes!". Vai até o cesto. Pega o porta-escova de dentes. Faz que escova os dentes.

Encontro: 07

Ação da pesquisadora: não houve retirada de brinquedos.

Cena 03

As crianças brincam de médico. João para Catarina: "Precisa de uma caneta para escrever as consultas do médico!". Catarina: "E também para a secretária!". João para pesquisadora: "Eu quero usar aquele negócio como caneta! (faca de madeira para passar patê)". Pesquisadora: "Então, pega". João pega a faca para patê. Faz que escreve com ela.

A necessidade de um objeto substituto remete à discussão realizada por Vigotski (2011) acerca do desenvolvimento cultural da criança. Esse desenvolvimento se dá por caminhos indiretos: quando uma ação direta da criança é impossibilitada, ela se vê obrigada a lançar mão de caminhos indiretos, ou, poderíamos dizer, mediados, pondo seu pensamento em movimento. Podemos dizer que recorre à palavra, signo cultural por excelência, para resolver o problema posto na situação imaginária.

No processo de escolha dos substitutos, a palavra se liberta do objeto, o que confere maior liberdade para a atividade lúdica: mesmo estando diante de um objeto que não se assemelhe ao objeto real ou brinquedo ausente, a criança suplanta essa concretude e passa a enxergar não mais o objeto em suas particularidades físicas, mas o significado que ele pode vir a ter. Nesse movimento, a experiência da criança, consubstanciada na palavra, é que dirige sua conduta, evidenciando os nexos entre a palavra e a ação. Isso significa, então, que o significado da palavra, nesse momento de desenvolvimento da criança, refere-se a tudo aquilo que ela conhece na sua experiência, com os usos sociais das coisas. Esse conhecimento, ainda bastante 
empírico, transforma-se na situação imaginária, em um conhecimento generalizado de sua experiência. Assim, o uso que a criança faz da palavra, nas situações em que procura um objeto substituto para o brinquedo ausente é indício de que a criança está dando passos rumo à transição para o pensamento conceitual, envolvendo a capacidade de abstração e generalização. Por isso, Vigotski (2008) compreendeu a brincadeira como a transição entre os processos de imaginação e pensamento.

No episódio de número 03, as situações imaginárias desenvolvem-se com a liberdade que o uso da palavra confere. Nenhum enredo torna-se preso aos brinquedos, ou melhor, à falta deles, pois é possível transferir o significado, fundado no conjunto de experiências da criança, do brinquedo ausente para outro objeto.

Dessa forma, uma vez instalada a situação imaginária, a falta dos brinquedos para completar a ação lúdica produziu uma condição na qual as crianças procuram objetos capazes de funcionar como substitutos, sendo que a conduta delas passa a ser direcionada pela palavra, o que movimenta processos em desenvolvimento na criança.

No processo da pesquisa surgiu a importância de conhecer o que causaria a retirada de brinquedos-alvo da ação, pois assim teríamos mais certeza de que a hipótese da retirada dos brinquedos que determinam as ações concretas, está correta. Assim, retiramos o fogão no encontro de número 05 da segunda fase. Qual foi a reação das crianças? Procurar um substituto. $O$ armário foi denominado como fogão.

Entretanto, nesse encontro, apenas João o utilizou, pois na situação imaginária criada pelos dois, João - o médico, além de receber os pacientes, também produzia os remédios e usava o fogão substituto para ferver suas fórmulas. Nos encontros de número 06 e 07 , as crianças não usaram o armário como substituto do fogão, logo ele foi esquecido, as crianças não interpretaram mais ações lúdicas de cozinhar no fogão, enquanto que os palitos continuaram sendo usados como talheres em todos os encontros: esses brinquedos parecem ocupar uma posição em que, a falta deles, não gera, pelo menos nesse momento do desenvolvimento, a necessidade de um substituto.

Assim, a posição que os brinquedos que determinam as ações concretas ocupam na situação imaginária faz com que sejam, prioritariamente, retirados. Eles se intercalam nas ações lúdicas e com outros brinquedos, de tal forma que a sua falta parece ser mais sentida pelas crianças do que os brinquedos-alvo das ações, provocando o uso da palavra para dirigir a conduta da criança.

\section{CONCLUSÕES}

A presente pesquisa refina o entendimento sobre os objetos sem significação específica na brincadeira e a importância da sua presença nos espaços onde as crianças brincam. Reafirma, ainda, a ideia defendida no campo da Educação Infantil sobre a necessidade de reduzir brinquedos industrializados, principalmente, os plásticos (Roveri, 2012) e a inserção de outros objetos como tecidos, madeira, areia, argila, papelão, sucatas para as crianças brincarem.

Pode-se também mencionar que o conhecimento produzido por esse trabalho contribui para fundamentar cientificamente a ação da professora e do professor em relação aos tipos de objetos que podem compor o espaço onde as crianças brincam e, ao mesmo tempo, auxilia a pensar no manejo deles, ou seja, quais objetos podem ser mantidos, retirados e inseridos.

Frisamos que não existe um momento marcado pelo critério de idade para a retirada dos brinquedos e a inserção dos objetos sem significação lúdica específica. O importante é identificar as transformações de significado que as crianças realizam e, gradualmente, realizar o manejo dos objetos. Dessa forma, a observação e registro da brincadeira são valorizados como ações metodológicas centrais da docência na Educação Infantil. Embora a metodologia utilizada tenha como foco principal a prática pedagógica, ela aprofunda o entendimento de como a Educação Infantil influi nos processos de aprendizagem e desenvolvimento das crianças. Nesse sentido, parece muito explícita a necessidade da criação de ambientes e situações para as crianças brincarem e como estas influem na aprendizagem e desenvolvimento.

Ainda sobre a metodologia da pesquisa ela pode comprovar ou refutar achados da pesquisa psicológica sobre o desenvolvimento dos processos psíquicos, mas essa metodologia ainda é raramente encontrada. Mais trabalhos que utilizem essa metodologia contribuem para seu aperfeiçoamento.

O recorte desta pesquisa foi sobre a utilização dos objetos na situação imaginária e como a atribuição de significados a certos objetos revela um rico movimento de trabalho no campo dos significados e, consequentemente, do pensamento. Demonstra que na situação imaginária importantes eventos relacionados a esse processo psicológico ocorrem (a separação entre palavra e objeto; a experiência da criança que se fixa na palavra, porém de forma generalizada dando base às ações sintéticas e abreviadas com objetos).

Decidimos que o melhor caminho era permitir que as crianças brincassem com brinquedos, objetos reais e objetos sem significação específica e relatar os momentos que se referem ao uso e escolha desses objetos. Há ainda muitos elementos ricos e importantes da brincadeira, como mediação da criança com mundo, que precisam ser estudados. Por exemplo, como o adulto - longe de posturas adultocêntricas - pode brincar com as crianças, contribuindo para a riqueza dos enredos e argumentos. 


\section{REFERÊNCIAS}

Aquino, L. M. L. de. (2015). Contribuições da teoria históricocultural para uma educação infantil como lugar das crianças e infâncias. Fractal: Revista de Psicologia, 27(1), 39-43. https://dx.doi.org/10.1590/1984-0292/1353

Brasil. Ministério da Educação. (2010). Secretaria de Educação Básica. Diretrizes curriculares nacionais para a educação infantil. Brasília: MEC, SEB. Recuperado de: http://www. uac.ufscar.br/domumentos-1/diretrizescurriculares_2012. pdf

Elkonim, D. B. (2009). Psicologia do Jogo. São Paulo: Martins Fontes.

Gobbi, M. (2010). Múltiplas linguagens de meninas e meninos na educação no cotidiano da Educação Infantil. Em Anais do I Seminário Currículo em Movimento. Belo Horizonte. Disponível em: http://portal.mec.gov.br/index. php?option=com_docman\&view=download \&alias $=6678$ multiplaslinguagens\&category_slug=setembro-2010pdf\&ltemid=30192

Gosso, Y.; Morais, M. de L S.; Otta, E. (2006). Pivôs utilizados nas brincadeiras de faz-de-conta de crianças brasileiras de cinco grupos culturais. Estud. Psicol. 11(1), 17-24.

Marcolino, S. (2013). A mediação pedagógica na educação infantil para o desenvolvimento da brincadeira de papéis sociais. (Tese de Doutorado). Universidade do Estado de São Paulo, Marília.

Marcolino, S.; Mello, S. A. (2015). Temas das brincadeiras de papéis na educação infantil. Psicologia: Ciência e Profissão [online]. 35(2), 457-472. http://dx.doi. org/10.1590/1982-370302432013

Mcloyd, V. C. (1983). The effects of the structure of play objects on the pretend play of low-income preschool children. Child
Development, 54(3), 626-635.

Marcolino, S.; Barros, F. C. O. M. de; \& Mello, S. A. (2014). A teoria do jogo de Elkonin e a educação infantil. Psicologia Escolar e Educacional, 18(1), 97-104. https://dx.doi. org/10.1590/S1413-85572014000100010

Mello, C. O. (1994). A interação social na brincadeira de fazde-conta: uma análise da dimensão meta-comunicativa. (Dissertação de Mestrado). Universidade Federal do Rio Grande do Sul, Porto Alegre.

Moura, M. O. de. (2004). Pesquisa colaborativa: um foco na ação formadora. In: Barbosa, R. L. L. (Eds.), Trajetórias e perspectivas da formação de educadores. (pp. 257-284). São Paulo: UNESP.

Roveri, F. T. (2012). Barbie na educação das meninas: do rosa ao choque. São Paulo: Annablume.

Teixeira, S. R. S.; Alves, J. M. (2008). O contexto das brincadeiras das crianças ribeirinhas da Ilha do Combu. Psicol. Reflex. Crit. [on-line] 21(3), 374-382. http://dx.doi.org/10.1590/ S0102-79722008000300005

Verba, L. (1993). Construction and sharing of meanings in pretend play among young children. In: Stambak; $\mathrm{H}$. Sinclair (Eds.), Pretend play among 3 year-olds (pp. 88-93). Hillsdale, N. J.: Erlbaum.

Vigotski, L. S. (2008). A brincadeira e o seu papel no desenvolvimento psíquico da criança. (Prestes, Z., Trad.). Revista Virtual De Gestão de Iniciativas Sociais. 1(8), 23-36.

Vigotski, L. S. (2011). A defectologia e o estudo do desenvolvimento e da educação da criança anormal. (Sales, D. R.; Oliveira, M. K. de; Marques, P. N., Trad.). Educ. Pesqui., 37(4), 863-869. http://dx.doi.org/10.1590/S151797022011000400012

A pesquisa obteve apoio financeiro do CNPq, via bolsa do Programa de Pós-Doutorado Junior (PDJ).

Recebido: 12 de maio de 2019

Aprovado: 05 de fevereiro de 2020 